\title{
Desde el silencio, historias de mujeres en la prisión
}

Sara Makowski Muchnik

FLACSO

Investigación sobre las formas de reconstrucción de la vida cotidiana a partir de la vivencia del encierro en una prisión de mujeres que cumplen una sentencia. Las particulares modalidades en que el tiempo y el espacio se reelaboran, aportan indicios de cómo pensar en la prisión no sólo como una institución profanadora del yo, sino también como un recurso para la resistencia y la redefinición de la subjetividad.

$\mathrm{E}$ n Seis propuestas para el próximo milenio, Italo Calvino desafía a lectores y a pensadores al afirmar que "la memoria está cubierta por capas de imágenes en añicos, como un depósito de desperdicios donde cada vez es más difícil que una figura logre, entre tantas, adquirir relieve". En las breves reflexiones que presento a continuación intento explorar, de manera muy general, los territorios silenciosos de una prisión de mujeres desde los cuales se reconstruye y se arma nuevamente la memoria, ese "depósito de desperdicios" que da relieve a la subjetividad y a la iden- tidad de las mujeres que habitan este espacio.

El ingreso a una institución carcelaria para el cumplimiento de una condena privativa de la libertad provoca en el campo de la experiencia una disolución de la vida cotidiana: los ritmos y los tiempos del mundo exterior poco a poco se disgregan, las relaciones sociales y los modos de interacción pierden su sustento. Aquellos supuestos fundamentos de la vida cotidiana comienzan a quebrarse junto con los ordenamientos coherentes y los contextos de sentido que habían conformado su vida cotidiana; nada aparece 
al principio como evidente y el sujeto encerrado pierde la plena convicción de que el mundo es tal como ha sido conocido por él. Las trayectorias y las experiencias biográficas deben ser readecuadas para contrarrestar la sensación de extranjerización -en la que nada es ubicado como familiar al principio-y comienza un largo camino de reexplicitación, ajuste y ampliación del acervo de conocimiento.

Como el poner en duda al conjunto de evidencias del mundo de la vida no puede ser algo permanente, a riesgo de caer en conductas autistas, lentamente se transita hacia una estabilización y una rutina de la vida en el interior de la prisión que va equilibrando nuevamente lo que posee un sentido y las estructuras significativas. Desde aquí comienza un intenso trabajo de reformulación y reelaboración de la vida cotidiana que tiene su anclaje en la modificación del vínculo con el mundo que se encuentra más allá de los muros.

Una de las rutas medulares que conducen a la reformulación de la vida cotidiana en una prisión de mujeres es la memoria. La posibilidad de olvidar y de recordar-labores, sentidos, afectos $\mathrm{y}$ valores- es uno de los primeros pasos en la recomposición de los componentes vitales del mundo cotidiano: el tiempo, el espacio y las formas de comunicación. Pero sobre todo, es el olvido la compañía permanente de las mujeres presas.

El olvido desempeña un doble juego: por un lado, las mujeres presas se convierten en ausencias al ser olvidadas por la familia y por las personas cercanas; por otro lado, aprenden ellas mismas a olvidar a los otros y al mundo exterior para poder reconstruir algo diferente. Las crueldades y complicidades que el olvido teje se visten de metáfora; sólo desde allí es posible enunciarlo. El ser olvidadas retumba por los huecos corredores de la cárcel, y una de las metáforas que más resonancia tiene es aquella que dice: "somos flores marchitas". Esta equiparación entre presas y flores alude a la función de reproducción -sexual, material y subjetiva- que la experiencia del encierro parece marchitar; hay un olvido de las presas como mujeres, como madres y como esposas.

El olvido cambia a las sentenciadas en mujeres ausentes y borradas de los recuerdos, y como una forma de violencia invisible las lleva muy lejos de la memoria. Al convertirse en parte de la vida cotidiana de las sentenciadas, el olvido se aprende a manejar y a ocultar; es la sensación del adentro que comienza a inscribirse en la experiencia del encierro y que por ello no debe traspasar los muros.

Así, en los momentos de la visita familiar, por ejemplo, las presas cuidan que no trascienda lo que para ellas significa la reclusión; tratan de disimular y ocultar la larga espera de una visita o los problemas cotidianos con los que tienen que lidiar. En el caso de las mujeres que tienen hijos fuera de la prisión, ${ }^{1}$ la situación es para ellas tan difícil que se oculta la verdad y, a veces, se prefiere el olvido de los hijos a ser recordadas como madres en prisión.

${ }^{1}$ Cabe mencionar que en México se permite la permanencia de los hijos de las internas en la prisión hasta la edad de seis años. 
Cuando el olvido proviene del esposo o compañero, es mucho más detonante aún porque es operador de transformaciones sustanciales de los atributos de identidad. En la mayoría de los casos es un olvido que se transforma en abandono y, desde aquí, se reformulan los afectos y los papeles de estas mujeres.

Cuando al olvido se opone el recuerdo del mundo exterior que aparece en los momentos de la visita familiar, éste sirve, entonces, como disruptor de la cotidianidad de la prisión porque inunda la memoria de relaciones olvidadas y de espacios distantes. Al mismo tiempo, el recuerdo redimensiona el olvido y lo fortalece porque muchas de esas imágenes que vuelven a la memoria comienzan a ser vividas con lejanía e incomprensión. El olvido sedimenta tan profundamente la experiencia del mundo exterior que aquello que la memoria se esfuerza en acercar parece no poder alcanzarse nunca, o al menos nunca en la misma forma que antes.

Pero por otra parte, el olvido es también un recurso: "para mal y para bien olvidamos. Empezando por la muerte, mil cosas olvidamos para vivir." $\mathrm{Al}$ interior de la prisión se crean "lugares de memoria" desde los cuales se ejerce un olvido selectivo; es así como se olvudan rostros y ruidos, la ciudad y el afuera, los colores y sabores. La experiencia del encierro se transforma en un filtro que sólo deja pasar a la memoria aquellas dimensiones del afuera que pueden ser procesadas por las nuevas circunstancias. Esta suspen-

\footnotetext{
${ }^{2}$ Mastretta, “Don", 1994.
}

sión de lo exterior es la puerta de acceso a la experimentación de nuevas sensaciones y a la redefinición de un mundo interno a la sombra del mundo exterior. Los otros, los de afuera, los esposos o compañeros y los familiares comienzan a ser olvidados por las propias internas; ellas no son sólo objeto de olvido sino que tienen también capacidad para olvidar.

Aprender a olvidar hace que algunos aspectos del mundo exterior se suspendan o se cancelen, de acuerdo con los tiempos de condena. En las situaciones de condenas extremadamente largas -25 años en casos de homicidio calificado, sin considerar remisiones parciales-, el mundo exterior se evapora, y hace muy difícil mantener latentes cometidos, deseos o espacios del afuera. Es en estos casos cuando el olvido se aproxima a la cancelación, y se constituye a partir de rompimientos con el exterior. En sentencias no extremadamente largas -de hasta diez años- es más común que ocurra la suspensión de una parte del mundo exterior, mientras que se mantienen presentes ciertos recuerdos que en algún momento podrán ser vividos como realidades (transformadas). En estos casos los olvidos se elaboran a partir de la distensión de los lazos con el exterior.

En relación con la reestructuración de la vida cotidiana, ejercer el olvido como recurso produce cambios significativos en la vivencia de la espacialidad. Al olvido de los espacios del afuera se le contrarresta con la experimentación de nuevas franjas de espacialidades que tienen otras fronteras y otras reglas de apropiación. La prisión 
de sentenciadas representa para las internas comenzar a reconocer nuevos espacios: sus límites, sus reglas y sus usos; pero sobre todo, otras formas de relaciones de poder y de violencia que las mujeres deberán aprender a manejar.

Por otra parte, cuando se experimentan de manera diferente las capas de espacialidad se transforman también las zonas de operación. El espacio inmediato de la prisión, el "aqué" asequible, desborda lo privado y está poblado por personas que no se conocen y que tienen segmentos vitales con pocos puntos de encuentro. Sin embargo, con el tiempo, las internas irán aprendiendo a vivir y a apropiarse de espacios extraños; conocerán sus reglas y las fronteras de la vigilancia y la autonomía. Porque a pesar de que en una institución total como lo es la cárcel los espacios están fijados por la propia institución, siempre existe la posibilidad de fabricarlos desde la propia vivencia.

Como puede sospecharse, la nueva espacialidad que se construye al interior de la cárcel de mujeres és inestable y compleja, y supone el aprendizaje y el conocimiento de normas, reglas y límites variables: un espacio seguro, por ejemplo, puede volverse en poco tiempo un espacio de vigilancia.

Un primer nivel de esta nueva espacialidad estará conformado por los espacios de vigilancia, que se caracterizan por ser espacios "oficiales" en los que se llevan a cabo las actividades institucionales y en los que se ejerce un férreo control sobre cada uno de los movimientos de las internas. Un se- gundo nivel es el del espacio que se localiza extra-muros, y se refiere al espacio exterior experimentado como no operable y distante, que aparece muchas veces como el lugar de la impotencia; es el lugar de los otros que continúa presente en la vida de las internas en la medida en que los tiempos de condena no terminen por diluirlo. Finalmente, se encuentran los espacios libres, que son ámbitos también institucionales pero objeto de uso y apropiación distintos por parte de las internas. Un salón del centro escolar o el espacio de un dormitorio, por ejemplo, pueden constituirse en espacios libres si allí se encuentran formas de ejercer cierta autonomía respecto de los ordenamientos institucionales.

Desde este mosaico fragmentado de espacios, entre los cuales se incluyen los ámbitos del mundo exterior que se olvidan o se recuerdan, se reconstruye la vida cotidiana de las mujeres en prisión.

Por otra parte, esta reformulación de la cotidianidad en el interior de la prisión se acompaña también de un entrecruzamiento particular de los diferentes ejes que conforman la temporalidad.

El transcurrir del tiempo social, que es el tiempo del mundo en general, depende de los tiempos de condena y de la asiduidad de las visitas familiares. Las mujeres sentenciadas que cumplen largos tiempos de condena tratan de matar el tiempo del afuera, de olvidarse de él y de acotar el mundo al tiempo de la prisión. El tiempo del mundo no se registra en sus acontecimientos; de todos modos el tiempo 
del calendario se inscribe en el cuerpo de estas mujeres dejando huellas de su paso inexorable: arrugas y envejecimiento, término del tiempo de la maternidad, etc. En los casos en los que las sentencias son de corto plazo, no es tan fácil desprenderse del reloj: el tiempo del mundo sigue vigente en los recuerdos, en las expectativas y en las visitas. No es posible en estas situaciones permanecer tan desconectadas del mundo porque "la cárcel no es eterna", y cuando la condena sea cumplida hay que ser parte nuevamente de la temporalidad del afuera. Cuando la condena se acerca a su fin, el tiempo del mundo se cuela entre las rejas y acelera la temporalidad cotidiana: se cuentan los días, se espera que pasen rápido los meses y se reflexiona sobre la cantidad de años que se pasó en el encierro.

El tiempo subjetivo, por su parte, que es el tiempo interior de la conciencia, se estructura a partir de los estados de ánimo y de las vivencias personales en el interior de la cárcel. Cuando la depresión y el abandono insisten con su ineludible presencia, "el tiempo es interminable, está suspendido y es un tiempo que desinfla", según dicen las mismas mujeres sentenciadas.

Con el tiempo subjetivo se mezcla el tiempo cotidiano, que transcurre al ritmo de las rutinas y las regularidades, de los ciclos y las repeticiones, y que se experimenta como repetición, ruptura y amnesia. ${ }^{3}$ En la cárcel de sentenciadas las repeticiones están

${ }^{3}$ Véase Balandier, "Sociología”, 1983. dadas por los horarios ya establecidos, por las actividades institucionales y por las rutinas que a lo largo de todo el día se repiten: vigilancia, control, registro a cada paso, revisiones. Esta rutinización le da al tiempo un carácter relativamente estable que produce una estabilización de las ansiedades provocadas por el abandono y el olvido, y por las irrupciones de las visitas familiares.

Pero en algunas situaciones el tiempo cotidiano puede producir rupturas que sacuden la monotonía y la repetición para hacerlas más soportables e, incluso, deseables. Las discontinuidades son impuestas por los momentos de la visita familiar que introducen fuertes cortes en la vivencia de la repetición: inundan de arritmias e incongruencias, y contagian con las urgencias del afuera. En las situaciones concretas, estos desfases son vividos como silencios, como incomprensión y como distancias insalvables. Las visitas son muy esperadas pero traen también el dolor de experimentar otro tiempo, que dificulta mucho la espontaneidad y la comunicación; por eso es tranquilizador para las internas volver después al tiempo de la repetición.

El tiempo de la cotidianidad permite olvidar aquello que escapa a sus horarios y rutinas, y se instaura como el tiempo predominante en la prisión: todo lo que ocurre fuera de él resulta extraño, disruptor, azaroso. Sumergirse en la repetición es una forma de olvidar y de matar algunas formas de exterioridad.

De esta temporalidad diversa que modula la experiencia del encierro se hace un procesamiento singular de 
acuerdo con aquellas vivencias privadas, biográficamente articuladas al acervo de conocimiento. En esta reelaboración de la temporalidad intervienen los recuerdos y las expectativas particulares que funcionan como ordenadores de la experimentación del tiempo.

Las vivencias de una espacialidad y de una temporalidad distintas entrañan cambios importantes en la subjetividad de las mujeres sentenciadas: hay una redefinición de las formas de interacción social y, con ello, una ampliación de los horizontes de la identidad. A medida que transcurren los años de condena y que se ocupan lugares y papeles distintos en el marco de la vida cotidiana de la prisión, las identidades se van modificando y con ello se transforman también los esquemas de referencia para la acción.

El complejo proceso de reconstrucción de la vida cotidiana que se da entre las mujeres sentenciadas ha revelado que la cárcel es también un espacio positivo y de recuperación. Entre los muros de la prisión se disuelven capas y sentidos de la subjetividad pero, a la vez, se rearma un sujeto con potencialidades para resistir y pensarse desde otro lugar.

En este rápido recorrido por una prisión de mujeres, la historia oral nos ha conducido hacia los pequeños fragmentos de lo cotidiano y nos ha traído voces desde el silencio del encierro. Y ha mostrado también que la memoria opera en el espacio de la prisión como componente a la vez disolutorio y constitutivo de las identidades que comienzan a reformularse en el ámbito de la experiencia y la interacción cotidiana.

Creo que desde esta memoria de olvidos y recuerdos una nueva figura ha logrado adquirir relieve. Sin que esto signifique, en lo más mínimo, opacar la maestría de la frase de Calvino.

\section{BIBILIOGRAFÍA}

-Balandier, George, "Sociología de lo cotidiano", Cabiers Internationaux de Sociologie, vol. LXXIV, 1983.

-Mastretta, Ángeles, "Don de olvido", Nexos, núm. 194, febrero, 1994. 